\title{
THE CURRENT STATUS OF THE EDUCATION AND TRAINING OF NURSE EDUCATORS IN SOUTH AFRICA
}

\author{
Professor Fhumulani Mavis Mulaudzi, University of Pretoria, \\ Dr Felicity M Daniels, University of the Western Cape, \\ Ms Kgomotso K Direko, North West University and \\ Professor Leana R Uys, University of KwaZulu-Natal
}

\begin{abstract}
Human resource for health is a global concern, with a shortage of doctors, nurses and midwives to meet the Millennium Development Goals. Nurses form the bulk of the healthcare workforce and are found to service remote areas where doctors are not available. The World Health Assembly in recognition of the human resource crisis passed resolutions for strengthening nursing and midwifery services. Nationally, the Forum for University Nursing Deans in South Africa (FUNDISA) realized that it was impossible to respond to the human resource crisis before ensuring that there is a supply of adequately trained nurse educators to train nurses and midwives in the country. Of specific concern was the lack of mentoring of young nurse educators and the high number of nurse educators who are within nine years of retirement which will potentially leave colleges and universities with inexperienced young nurse educators. These challenges incited FUNDISA to conduct a survey in 2011, to determine the current status of nurse educator education and training in South Africa. Newly qualified nurse educators, heads of colleges and university nursing departments and heads of higher education institutions which offer nursing education programmes participated in 3 separate surveys. Senior nursing academics conducted the document review and evaluated nine sample curricula. The results revealed that nurse education programmes are offered at Diploma, Degree, and Master's level. Educators felt better equipped in certain educational activities than in others. Their orientation to an academic setting and performing new tasks was reported as inadequate. Their self-rating of their competency fell between "poorly prepared" and "adequately prepared" with the lowest rating on curriculum development and highest rating on being a role model. On average the heads of NEI rated the neophytes higher than they rate themselves, however they rate the neophytes lower on role modeling professional behaviour, participating in scholarly activities and participating in the activities of the NEI. Conference attendance, in-service training and formal mentorship were the most common support offered to neophytes. Review of existing curricular highlighted several gaps in programmes offered at diploma, degree and master's level. The study recommends standardization of nursing education curricular; increased practical exposure for nursing education students; increased capacity-building programmes and regular assessment of core competencies of nurse educators to ensure relevance and currency.
\end{abstract}

Keywords: MDG; Nursing Education; shortage of medical staff 


\section{Introduction}

The World Health Organization estimated a global shortage of 2.3 million physicians, nurses and midwives to meet the workforce levels required to strengthen health systems and accelerate progress towards attaining the health-related Millennium Development Goals (MDGs) (WHO 2006). Recognizing that pressing health needs across the globe cannot be met without a competent, adequate and available health workforce, an urgent and sustained scale-up of training within the health workforce was recommended for both developed and developing countries to address the health crisis.

Sub-Saharan Africa alone needs approximately 600,000 additional nurses to meet the average density coverage for low-income countries in order to achieve the MDGs (Buchan and Calman, 2004). Nurses are arguably the most important healthcare workers available in most Sub-Saharan nations because they perform a broad range of tasks and often work in settings where no other health workers, including physicians, are available. Thus, nurses form the bulk of the healthcare workforce. Generally, nursing shortages have a negative impact on patient care and are costly to the healthcare industry. A significant nursing shortage exists, particularly in acute and long-term care settings. The situation is worse in poor, impoverished settings (Chen, Evans, Anand, Boufford, Brown, Chowdhury, et al, 2004).

Recognizing the human resource crisis in the health field, the World Health Assembly (WHA) passed resolutions WHA54.12 and WHA59.27 in May 2001 and again in 2006 for strengthening nursing and midwifery services. Resolution WHA54.12 and its strategic plan of action provided for Strategic Direction for Strengthening Nursing and Midwifery (SDNM). Henceforth, national policies and interventions were advocated to improve Human Resource for Health $(\mathrm{HRH})$ planning, management, education, practice, and leadership of nurses and midwives (WHO, 2010). Resolution WHA59.27 "urges Member States to confirm their commitment to strengthen nursing and midwifery by establishing comprehensive programs for the development of human resources, actively involving nurses and midwives, ensuring continued progress toward implementation of WHO's strategic directions for nursing and midwifery." It was agreed that continued international efforts and commitments made towards improving global nursing and midwifery workforce strategies are very important. Since then, indicators of some progress towards improvement of the nursing and midwifery workforce are evident in publications and declarations of the Chiang Mai Declaration (2008), Kampala Declaration and Agenda for Global Action (2008), and the WHO Regional Office for the Western Pacific Strategic plans for strengthening health systems (WHO 2008). However, these documents call for greater government commitment to maintaining efforts in improving the healthcare workforce.

This is highlighted in the recent, major global health initiatives, e.g. the Global Fund to Fight AIDS, Tuberculosis (TB) and Malaria (GFATM); the Global Alliance for Vaccines and Immunization (GAVI); and Stop TB, where substantial amounts of money were raised only to have their potential effectiveness constrained by health workforce problems (Lane \& Glassman, 2007). In 2010, PEPFAR and the WHO launched a major initiative for the up-scaling of transformative health professional education. This means that not only the quantity of health professionals should be improved dramatically, but the quality should also be addressed. 


\section{The South African situation}

FUNDISA realized that it is impossible to increase the number of educated and trained nurses without first ensuring that an adequate supply of nurse educators of the appropriate quality is available. In South Africa, the Nursing Education qualification is a post-registration programme which is offered at universities. The qualification prepares nurses to be educators who are most often employed by colleges and universities. They are tasked with the responsibility of educating and training nurses who will render care to patients. Currently, the South Africa Nursing Council (SANC) has about 10000 nurse educators registered, with only a marginal increase every year.

Although universities in South Africa are producing large numbers of nurse educators, they do not seem to be absorbed by colleges and universities (Genius, Management Solutions 2010: 51). In addition, the lack of mentoring of young nurse educators remains a concern. Compounding these problems is the fact that a total of 272 of the educators in nursing colleges are within nine years of retirement and will have to be replaced during the next ten years. This will leave colleges and universities with inexperienced young nurse educators. The nurse educator: student ratio is on average 1:16. However, the ratios in different nursing education institutions vary enormously. An increase in the number of students trained, based on the country's response to the nurse shortage, results in large classes which may affect the standard and quality of education and the format or teaching strategy that a lecturer is expected to use. These problems, as well as the realization that it is imperative to ensure that universities are delivering quality nurse-educators before increasing the numbers produced, led FUNDISA to initiate a survey of nurse educator education in 2011. Changes in the education environment require a review of programme delivery to ensure its relevance and appropriateness, and to ensure that programmes respond to societal needs. The quality of the preparation of nurse educators can best be described in terms of the curriculum, assessments, clinical experiential learning and type of qualifications (Kalb 2008: 217).

Nurse educator competency is regarded as important and the core of a nurse educator programme. Kalb (2008: 217) maintains that core competencies are important as they provide standards and direction in the nursing educator programme. In 2011, the SA Nursing Council initiated a system of identifying the competencies of a nurse educator. As a contribution to this process, FUNDISA developed a set of competencies which it proposed to the SANC. While the SANC process has not been completed, FUNDISA is continuing to use their set of competencies as a framework for their work.

Although minimum standards for the nurse educator program are set by SANC regulations, the format and structure differ from one university to other. Some universities offer a one-year diploma in nursing education, while others offer a three-year degree. Some make provision for education leading to registration solely as a Nurse Educator, while others also make provision for an advanced nurse educator, usually at Master's level. It is obvious then that the outcome of the different programme offerings, in terms of the competency of nurse educators, differs markedly. 


\section{Purpose of the study}

The purpose of the study on which this chapter is based was to determine the current status of nurse educator education and training in South Africa, using a list of 14 nurse educator competencies as the standard (see Table 2 for the complete list of competencies).

The objectives were to evaluate existing nursing education programmes and the preparation of new nurse educators in terms of:

- The perceptions of newly-qualified nurse educators and their preparation to become nurse educators;

- The perceptions of heads of nursing education institutions with newly qualified nurse educators;

- The current qualifications, registration and completion rates of different nurse educator programmes;

- The quality of the nurse educator curricula;

- To identify gaps in order to assist in developing relevant, acceptable guidelines so that nurse education preparation will address the needs of the country.

\section{Research design and methods}

The study adopted a mixed method approach, with a quantitative as well as a document survey of curricula and a group discussion of these.

\section{Population and sample}

Survey samples: The first sample involved all newly qualified nurse educators who had been working in nursing colleges or university nursing departments for 5 years or less. The second sample comprised the heads of all colleges and university nursing departments who had employed new nurse educators during the past five years. The third sample was composed of the heads of all higher education institutions which offer a nursing education programme $(n=18)$.

Document review and evaluation: The group who reviewed the nine sample curricula received consisted of senior nursing academics who attended the September 2011 meeting of FUNDISA. Usually the heads of nursing schools and a secundus from the same university attend these meetings. However, in this case we specifically asked heads to bring nurse educators who were teaching nursing education. All heads have to be registered nurse educators.

\section{Research instruments}

Three survey questionnaires were developed by the project team based on the competencies for nurse educators developed by FUNDISA. The first questionnaire for recently qualified nurse educators asked them to rate themselves in terms of their preparation in each of the competencies on a scale of 4 to 1 (very well prepared, adequately prepared, poorly prepared and uncertain). It also requested demographic information and a list of areas in which they thought they were adequately prepared, and another list for areas of inadequate preparation.

The second questionnaire was for the heads of colleges and universities who had appointed the nurse educators who qualified in various institutions. It essentially followed the same format as that for the newly qualified nurse educators, but also included a few questions about workforce issues and capacity building. 
The third questionnaire was developed for the providers of nurse educator education programmes. It dealt with the kind of programme they offer, the qualifications of the teachers, and the production or throughput over the last few years. It also asked the institution to provide a complete macro-curriculum. The curricula submitted were discussed in focus groups during a scheduled FUNDISA meeting. Each focus group dealt with two curricula, and each had to evaluate the curriculum's adequacy in terms of addressing the nurse educator competencies.

\section{Data collection process and analysis}

The research was introduced to the heads of departments of higher education institutions and colleges at their national meetings and requested them to encourage their staff to take part in the study. Data collection was conducted between May and July.2011. The questionnaires were e-mailed to all colleges and university departments. The response was very poor, despite follow-up. The qualitative data was analyzed manually and descriptive statistics were used to describe and summarise the data.

\section{Validity and reliability}

Content validity, which refers to judgements, was ensured by using the competencies in the existing FUNDISA to design the questionnaire. The objectives also guided the process. An expert in nursing education was also consulted to check the content of the questionnaire. Face validity refers to the researcher's subjective assessment of the presentation and relevance of the questionnaire. Burns and Grove (2007) assert that an instrument is reliable if it can yield the same measure if used on more than one occasion. The instrument's reliability was tested by using a pre-test. Pre-testing of the instrument was done by sending each questionnaire to a few participants to check if questions could be answered with ease. The results showed that some of the questions were double- barrelled, ambiguous and difficult to answer. The questions were changed as suggested. Reliability of the study was increased by using two "user" groups as respondents, as well as two "provider" sources, and utilising both quantitative and qualitative data.

\section{Findings of the study}

The findings of the study are presented in the form of tables and graphs.

\section{Perceptions of recently qualified nurse educators}

Only six nurse educators who were appointed in nursing education institutions in the past five years responded. They were employed at six different NEls. Of those, five were females and one was male. Their age range was as follows: one (1) participant was in her twenties, three (3) were in their thirties, one (1) in her forties and one (1) in her fifties. Three of them had a Master's degree, one had a bachelor's degree and one had a diploma. One participant did not answer the question. All the participants had been appointed since 2008. They all studied part-time and their studies were selffunded in all cases.

The results showed that the lecturers felt that they were more well-equipped in certain activities than they were in others (see Table 1). New nurse educators felt that their orientation to an academic setting and their preparation for doing things for the first time was inadequate. One of the topics mentioned as a strength by two of the neophytes (clinical facilitation) were experienced as a weakness by another. 
Table 7.1: Strength and weaknesses of their preparation as seen by different groups

\begin{tabular}{|c|c|}
\hline Stren & Wea \\
\hline $\begin{array}{l}\text { New nurse educators only } \\
\text { - } \quad \text { Preparing lesson plans or media (3) }\end{array}$ & $\begin{array}{l}\text { New nurse educators only } \\
\text { - Setting tests and examinations and designing } \\
\text { assessment tools ( } 3 \text { ) }\end{array}$ \\
\hline $\begin{array}{l}\text { Identifying learning objectives and } \\
\text { course content (2) }\end{array}$ & $\begin{array}{l}\text { - Compiling a study guide and curriculum } \\
\text { development (2) }\end{array}$ \\
\hline $\begin{array}{l}\text { Specific subjects (nutrition, general } \\
\text { nursing, anatomy and physiology) (3) }\end{array}$ & $\begin{array}{l}\text { - Aspects of academic management, such as } \\
\text { time management, dealing with student issues } \\
\text { and record keeping (2) }\end{array}$ \\
\hline PBL facilitation & inations and writing reports \\
\hline $\begin{array}{l}\text { NEIs who only use nurse educators } \\
\text { - Field visits } \\
\text { - Curriculum development } \\
\text { - Assessment of students (theory and } \\
\text { practica) (2) }\end{array}$ & $\begin{array}{l}\text { NEIs who only use nurse educators } \\
\text { - } \quad \text { Following SANC guidelines } \\
\text { - } \quad \text { Proper record-keeping } \\
\text { - } \quad \text { Continuous assessment and other clinical } \\
\text { - } \quad \text { crojects (2) } \\
\text { - } \quad \text { and studical issues in nursing practice such as ethics } \\
\text { Changes in the health sector }\end{array}$ \\
\hline $\begin{array}{l}\text { Both groups } \\
\text { - Theory and practice of teaching/giving } \\
\text { lectures or facilitation in class ( } 8 \text { ) } \\
\text { - Clinical facilitation (4) }\end{array}$ & $\begin{array}{l}\text { Both groups } \\
\text { - } \quad \text { Curriculum development and issues }\end{array}$ \\
\hline
\end{tabular}

The rating of neophytes of their own competency falls between "poorly prepared" and "adequately prepared", with an average of 2.7 (see Table 2). They rate themselves lowest on curriculum development (competency 1 ) and highest on being a role model (competency 7 ). 
Table 7.2: Rating in terms of competencies by newly-qualified educators and heads of NEls.

\begin{tabular}{|c|c|c|c|}
\hline No & Competency & $\begin{array}{l}\text { Average self- } \\
\text { rating by newly } \\
\text { qualified NEs }\end{array}$ & $\begin{array}{l}\text { Average of NEls } \\
\text { heads }\end{array}$ \\
\hline 1 & $\begin{array}{l}\text { Develop a curriculum that is relevant, evidence-based and } \\
\text { competency focused }\end{array}$ & 2 & 3.3 \\
\hline 2 & $\begin{array}{l}\text { Develop micro-curriculum material (course outlines, } \\
\text { assessment instruments, teaching material) to support the } \\
\text { implementation of a macro-curriculum }\end{array}$ & 2.2 & 3 \\
\hline 3 & $\begin{array}{l}\text { Create an environment in classroom, laboratory and clinical } \\
\text { settings that facilitates student learning and achievement of } \\
\text { competence }\end{array}$ & 3 & 3.7 \\
\hline 4 & $\begin{array}{l}\text { Use a variety of teaching modalities to promote learning and } \\
\text { mastery in nursing students }\end{array}$ & 2.7 & 3.7 \\
\hline 5 & $\begin{array}{l}\text { Creatively integrate reliable and valid formative and } \\
\text { summative assessment of students in a teaching/learning } \\
\text { programme, in classroom, laboratories and clinical settings, } \\
\text { and in all domains of learning }\end{array}$ & 2.7 & 3.3 \\
\hline 6 & $\begin{array}{l}\text { Promote clinical competence by exposing students to } \\
\text { appropriately chosen and structured clinical experiential } \\
\text { learning }\end{array}$ & 3 & 3.3 \\
\hline 7 & $\begin{array}{l}\text { Model clinical competence and professional behaviour and } \\
\text { ethos }\end{array}$ & 3.2 & 3 \\
\hline 8 & $\begin{array}{l}\text { Supervise clinical preceptors and/or a team of teachers } \\
\text { working with the students they are teaching to ensure } \\
\text { quality, staff development, optimal linking of theory with } \\
\text { practice and support }\end{array}$ & 2.7 & 2.7 \\
\hline 9 & $\begin{array}{l}\text { Implement appropriate strategies of quality assurance of the } \\
\text { clinical and classroom learning experiences of students }\end{array}$ & 2.3 & 3 \\
\hline 10 & Keep adequate teaching records of all teaching activities & 2.5 & 3.3 \\
\hline 11 & $\begin{array}{l}\text { Function as change agents and leaders to create a preferred } \\
\text { future for nursing education and nursing practice }\end{array}$ & 2.2 & 3 \\
\hline 12 & Maintain own competence as a nurse and an educator & 3 & 3.3 \\
\hline 13 & $\begin{array}{l}\text { Participate in scholarly activities such as doing research and } \\
\text { writing scholarly works }\end{array}$ & 2.8 & 2.7 \\
\hline \multirow[t]{2}{*}{14} & $\begin{array}{l}\text { Participate in the educational environment to support the } \\
\text { work of the institution and the good of the educational } \\
\text { process }\end{array}$ & 3.2 & 3 \\
\hline & Average rating & 2.7 & 3.2 \\
\hline
\end{tabular}




\section{The perceptions of heads of NEIs}

The response from heads of NEls was poor, as the heads of only 5 departments responded. Of those three (3) were public colleges (out of a total of nine colleges in the country) and two (2) were public schools (usually attached to a college). Three of the NEls who responded had not appointed any newlyqualified educators in the last three years, two appointed one, and one appointed ten.

The NEls who responded varied in their workforce from 132 permanent posts to 5 permanent posts. One of the institutions had 18 vacant positions, while two had 5 vacant positions and the other two were fully staffed. The staff to student ratio ranged between 1: 6.6 medium sized college to 1: 60 in a large college with 18 vacant positions. The average ratio was 1:24.

\section{Table 7.3: Capacity building activities}

\begin{tabular}{|l|l|}
\hline Strategy & $\begin{array}{l}\text { Number of NEls using this } \\
\text { strategy }(\mathbf{n}=\mathbf{5})\end{array}$ \\
\hline Supported to attend relevant conferences & 5 \\
\hline In-service training & 4 \\
\hline Offers formal mentorship & 5 \\
\hline Fund postgraduate education & 2 \\
\hline Has a budget for capacity-building & 1 \\
\hline
\end{tabular}

As illustrated in Table 3, the most common approach to capacity-building was attendance of relevant conferences, in-house in-service training and formal mentorship. Two institutions indicated that they supported educators in furthering their studies. However, only one institution had a budget of R4000 per staff member per annum for capacity development.

On average (see Table 2) the heads of NEI rate the newly appointed nurse educators higher than they rate themselves (3.2 compared with 2.7 from a total of 4). This means that the generally believe them to be adequately and very well prepared. However, in three competencies, they rate the neophytes lower than they rate themselves - role modelling professional behaviour (7), participating in scholarly activities (13) and participating in the activities of the NEI (14).

When asked to list the most important areas in which neophytes were inadequately and adequately prepared, the two groups agreed that they were adequately prepared for classroom teaching and for clinical facilitation, and inadequately prepared for curriculum development (see Table 1). However, when read together, the heads of NEls seem to want educators to be more competent in the general formative aspects, such as knowing the professional issues, health policies and educational management (both Table 1 and 2).

Forty-seven percent, nine of 19 , university nursing schools that prepare nurse educators responded as part of the survey for universities preparing nurse educators. The highest qualifications of the respondents were as follows: six (6) had A PhD Degree, 3 had a Master's Degree and 1 had a Bachelor's degree. With reference to the nursing education qualification offered: four (4) institutions offered nursing education as a Bachelor's Degree qualification, three (3) offered it as a diploma, one (1) offered a nursing education programme at Master's Degree level, while one offered a PhD in nursing education. 
The years of experience of their nurse educators ranged from 4 to 35 years, with an average of 20.7 years.

Table 7.4: Programme credits

\begin{tabular}{|l|l|l|}
\hline Qualification & $\begin{array}{l}\text { Credits (each 10 notional hours of student } \\
\text { involvement) }\end{array}$ & Duration \\
\hline Diploma $(n=3)$ & 120,144 & 1 year \\
\hline Bachelor's Degree $(n=4)$ & $376 ; 424$ & 3 years \\
\hline Master's Degree $(n=1)$ & 320 & 2 years \\
\hline
\end{tabular}

The programme is offered at Diploma, Degree, and at Master's level. Credits differed from one institution to the other e.g. the total credits for a one-year Diploma programme may be 120 credits at one institution, while at another the total number of credits for the same programme has a total of 144 credits.

NEls preparing nurse educators were asked about the trends in graduating students, and the results are summarized in Table 5. In the corresponding period, the SA Nursing Council reported that 11383 nurse educators were on their registers, and that 559 new nurse educators were registered in 2010 (www.sanc.co.za). Table 5 shows that very few students qualify as nurse educators through either the diploma or the Master's degree as the programme for qualifying as a nurse educator.

Table 7.5: Students graduating from different programmes from 2008 to 2010

\begin{tabular}{|l|l|l|l|l|}
\hline Qualification & $\mathbf{2 0 0 8}$ & $\mathbf{2 0 0 9}$ & $\mathbf{2 0 1 0}$ & Total \\
\hline Advanced Diploma $(\mathrm{n}=3)$ & 28 & 33 & 59 & 120 \\
\hline Bachelor's Degree $(\mathrm{n}=4)$ & 220 & 281 & 387 & 888 \\
\hline Master's $(\mathrm{n}=2)$ & 7 & 8 & 9 & 24 \\
\hline
\end{tabular}

\section{Document review about the adequacy of curricula}

The group of 32 senior academics from 19 of the 22 University Nursing Schools divided into three small groups and each group reviewed a set of curricula. The aim was to identify quality and quantity gaps when the curricula were compared to the list of nurse educator competencies. The identified gaps from each group are listed, with the type of programme scrutinized.

Review of the Diploma Curricula identified the following gaps:

- Curriculum development was not expected from students;

- Competencies 11,12,13 and 14 were not addressed at all;

- Identified words linked to competencies were not necessarily directed at competence itself (theory not practice;

- Quality Assurance was not addressed;

- $\quad$ Students were not exposed to clinical teaching;

- Aspects such as ethics and professional role-modelling were not addressed; 
- Aspects of educational management such as keeping of adequate teaching records and participating in scholarly activities were not addressed

In a review of the Master's Curricula, the following gaps were identified:

- Evidence which the group finds of competencies being addressed is implied rather than explicit in the programme;

- Reference to actual competencies was generally lacking;

- There was no preceptor/team supervision exposure;

- $\quad$ They also identified the same gaps as group 1.

In the review of the B-degrees the following gaps were identified:

- Variety of teaching modalities not adequately addressed;

- Creative integration of valid assessment methods not adequately addressed;

- The curricula generally lacked clear educational outcomes, since many of them combined preparation as a nurse manager with the preparation of a nurse educator, and the programmes seemed to focus more strongly on the management outcomes. There was a lack of balance in the total programme between administration and education.

\section{Discussion}

The results of this study were discussed at a plenary session of FUNDISA. This meeting identified principles for a task team to develop guidelines for the preparation of nurse educators:

- There should be agreement sought on the body of knowledge that creates a nurse educator, or which prepares a person to be competent in all 14 competencies.

- The use of terminology should be standardized across all programmes;

- Schools should be urged to ensure congruency between the title and content of modules;

- Consensus should be established on the list of competencies about electronic teaching technology;

- At the level of Higher Education Institutions, academics should be technologically capable;

- A blended approach should be followed, including both old (overhead projectors) and newer equipment (computer-based teaching);

- In-service training for existing Nurse Educators in newer approaches such as simulation should be established;

- Clinical training: role-taking (students working as nurses as part of a service-rendering team) and skills development (students working with patients or clients just to learn a specific skill) should be adequately represented and identified;

- The practical exposure requirements or practice teaching of candidate nurse educators should be clearly stipulated;

- Balance in outcomes to reflect importance.

- Content- appropriate e.g. Anatomy and Physiology

- Entry requirements should be identified

- $\quad$ Proposed qualifications/NQF levels should be identified

- Negotiations re study leave should be explored

- Internship should be explored 
- Funding for studies in nursing education

- Number of hours of practice should be stipulated

The results show that only a few newly-qualified educators are being appointed in nursing colleges and nursing departments at universities. Of those who are being appointed, the majority are middle-aged.

The profession is struggling to attract young professional nurses to nursing education. This can be attributed to many factors: e.g. nurse educators do not benefit from an Occupation-Specific Dispensation (OSD) which provides financial incentives for additional clinical qualifications when one works in clinical settings, but not when one is involved in nursing education.

The results also showed that the newly-qualified educators viewed themselves as being less competent in performing some of the expected tasks such as curriculum development and designing a microcurriculum, as well as in leadership. They viewed their strong point as pertaining to the clinical accompaniment of students for experiential learning. The results corresponded well with the views of the users regarding the newly-qualified personnel whom they appointed. Another weak point that was cited by the users was the designing of assessment tools. These are critical, as they are used to rate the formative and summative performance of student nurses. It is important that the tools should be able to measure knowledge, skills and attitudes, and be appropriate for the learning objectives and teaching strategies employed, as noted in Halstead (2007: 80). Guilbert explains an educational cycle which includes objectives, programme implementation and evaluation or assessment, and these must be closely related. (1977: 300).

The results from the users showed that there is a shortage of lecturers and many vacant posts which have not been filled in the institutions. This affects quality teaching as the ratio of students to lecturers will be high. The ratio ranged from 1: 6.6-1: 60. The users indicated that there are capacity-building initiatives in their institutions. However, in certain institutions there is no budget for such activities, while for those that have a budget, only a limited amount is provided which makes it difficult for the lecturers to attend training due to the rising costs of continuing education and in-service training activities.

A challenge in the production of nurse educators was also clear, as the figures produced in a year are minimal. The results showed that the degree programmes produce more nurse educators than the Diploma and Master's qualifications do.

\section{Recommendations}

Nurse educators must increase the hours spent in practica and other tasks such as curriculum planning and design. The practica times in terms of designing lesson plans and teaching must be increased so that students gain confidence. It has been recommended that the nursing education curriculum and qualification be standardised countrywide. Continuous development of nurse educators must be encouraged and a budget must be provided for capacity-building programmes. Core competencies must be stressed and evaluated at all times so as to ensure relevance and currency. More research needs to be done to examine the curricula of different institutions. 


\section{Conclusions}

The results showed that there is a shortage of nurse educators and a lack of uniformity in the way that the programme is offered. There is a need to advance the training of nurse educators. At the same time, the quality of the nurse educator training program needs to be updated by ensuring a standardized competency-based curriculum which will be offered in all institutions.

\section{References}

Andersson. E. 1999. From vocational training to academic education: the situation of the schools of nursing in Sweden. The Journal of Nursing Education 38(1): 33-8.

Benner, P., Sutphen, M., Leonard, V., Day, L. 2009. Educating Nurses: A Call for Radical

Transformation. Carnegie Foundation for the Advancement of Teaching: Jossey-Bass.

Buchan, J., and Calman, L. 2004. The Global Shortage of Registered Nurses: An Overview of Issues and Actions. Geneva: International Council of Nurses.

Chen, L., Evans, T., Anand, S., Boufford, J.I., Brown, H., Chowdhury, M., Cueto, M., Dare, L., Dussault, G., Elzinga, G., et al. 2004. Human resources for health: overcoming the crisis. Lancet 364: 1984-1990.

Habel, M., and Kim, A. 2010. Teaching Tomorrow's Nurses. Nursing Spectrum (3): 50-54.

Carr, G. 2007. Changes in nurse education: being a nurse teacher. Nurse Education Today 27: 893-899. Genius Management Solutions. 2010 Audit of Public Nursing Colleges and Schools. Pretoria.

Guilbert, J.J. 2007. Educational Handbook for Health Personnel. WHO Offset Publication no 35. World Health Organization: Geneva.

Halstead, J.A. 2007. Nurse Educator Competencies: Creating an evidence - based Practice for Nurse Educators. New York: National League for Nursing.

Kalb, K.A. 2008. Core Competencies of Nurse Educators: Inspiring Excellence in Nurse Educator Practice. Nursing Education Perspective 29(4): 217-219.

Lane, C. and Glassman, A. 2007. Bigger and better? Scaling up and innovation in health aid. Health Affairs 26 (4): 935-948.

World Health Organization 2006. World Health Report 2006: Working together for health. World Health Organization: Geneva.

World Health Organisation 2010. Strategic Direction for Strengthening Nursing and Midwifery Services 2011 - 2015. World Health Organization: Geneva. 